\title{
QUERO A FOME DE CALAR-ME (SOBRE A POESIA DE DANIEL FARIA)
}

Marcos Lopes*

(D) https://orcid.org/0000-0002-9706-1314

Como citar este artigo: LOPES, M. Quero a fome de calar-me (sobre a poesia de Daniel Faria). Todas as Letras - Revista de Lingua e Literatura, São Paulo, v. 23, n. 3, p. 1-13, set./dez. 2021. DOI 10.5935/1980-6914/eLETDO2114945

Submissão: novembro de 2021. Aceite: novembro de 2021.

Resumo: Este ensaio discute a poética de Daniel Faria e sua inserção em uma tradição espiritual e bíblica. O núcleo temático das análises, formado pelos binômios "silêncio e palavra" e "veste e nudez", é acompanhado da formulação de duas hipóteses de trabalho: a primeira afirma que o poema é um corpo intransponivel, pois a singularidade expressiva da linguagem artística não se traduz completamente no campo conceitual de uma disciplina científica; a segunda hipótese propõe que essa irredutibilidade do poema a um campo conceitual se deve ao estatuto da metáfora (a polissemia de sentido).

Palavras-chave: Daniel Faria. Nudez. Graça. Literatura e Bíblia. Metáfora.

\section{VITA BREVIS, ARS LONGA}

E saibamos que seremos ouvidos, não com o muito falar, mas com a pureza do coração e a compunção das lágrimas.

A Regra de São Bento, Capítulo XX, Da Reverência na Oração 
[...] por isso, fale pouco. Das muitas ocupações brotam sonhos; do muito falar nasce a prosa vã do tolo.

Eclesiastes 5:3

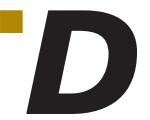
aniel Faria (1971-1999), poeta português e noviço da Ordem dos Beneditinos, morreu aos 28 anos de idade. Sua morte foi provocada por um acidente doméstico e trágico: uma queda, que o fez entrar em coma, do qual não retornou mais (GARCIA, 2019, p. 3). Ao poeta noviço caberia um preceito da sabedoria antiga, evocado por Fernando Pessoa em um texto dedicado a Mário de Sá-Carneiro: "Morre jovem o que os Deuses amam”. E ao especificar os três tipos privilegiados de relação com a divindade, Fernando Pessoa (2005, p. 455) explicaria que "os Deuses são amigos do herói, compadecem-se do santo; só ao gênio, porém, é que verdadeiramente amam". Na categoria de gênio, para o autor de Mensagem, inscreve-se a figura do poeta, que excede o comum dos mortais, recebendo dos deuses a potência da criação, que o torna semelhante a esses últimos.

É fato que aquele preceito de sabedoria antiga se refere à noção de destino ou de fado, que entende o curso das ações humanas ferido de uma radical contingência e à mercê de algo superior à razão humana (os seres humanos são mortais e para esses últimos a única forma de imortalidade possivel seria perdurar na memória das gerações vindouras por seus feitos e obras cantados pelos poetas). Também é fato que essa ideia de algo que excede a compreensão humana pode ser relacionada a uma cultura religiosa em Portugal, que, talvez, ao culto politeísta antigo soube corresponder com a devoção católica dos santos, embora não sendo deuses evidentemente, constituíram aquele conjunto de intercessores na dura travessia terrena para homens e mulheres. Curiosamente, à tríade tipológica de Fernando Pessoa, com traços distintos e aparentemente incomunicáveis, a poesia de Daniel Faria responde com uma aproximação entre as figuras do santo e do poeta.

Daniel Faria deixou uma obra impar, que dialoga não apenas com uma tradição literária portuguesa, o que já não seria desprezivel, em se tratando da arte verbal, mas com questões intrincadas à filosofia, à espiritualidade cristã, como, por exemplo, a ascese, a mística e a própria teologia. É o que acompanhamos na leitura deste poema transcrito.

\section{ASCESE}

Há os que se deitam sobre a relva

Como sombras que dormem sobre túmulos

Tu, porém, dormes sobre a morte

A longa ausência que há dentro dos poemas

(FARIA, 2009, p. 399).

Diferentemente de Fernando Pessoa ou de Mário de Sá-Carneiro, poetas que, cada um a seu modo, produziram uma intrincada criação artística sobre a fragmentação do eu na modernidade e que foram capazes de pensar poeticamente com e contra essa modernidade, Daniel Faria escreveu e inscreveu sua poesia com base na experiência religiosa do catolicismo, mas afinando sua dicção pós-moderna no canto de poetas identificados com uma tradição ontológica, como, por exemplo, F. Hölderlin e Rainer Maria Rilke ou 
[...] os portugueses Ruy Belo e Herberto Helder no que estes têm (ainda que diferentes entre si) de tensionadores da relação entre o humano e o sagrado, entre o mundo presente e comezinho, entre a palavra poética fundadora de mundos e a palaura cotidiana,

segundo a percuciente formulação de Ida Alves (2007, p. 105-106). A poesia de Daniel Faria radica seu etos na milenar tradição espiritual do monasticismo, na experimentação e inovação semântica e formal das mais ousadas poéticas do século XX.

Como poeta da década de 1990, Daniel Faria, no que diz respeito ao momento histórico da religião e da sociedade em geral, compartilha com os seus coetâneos a experiência religiosa de um pós-ateísmo, o fim das utopias socialistas e, certamente, das vanguardas artísticas, que tanto turbinaram as lutas políticas e culturais no século XX. Com o termo pós-ateísmo, entendamos, nos limites e propósitos deste ensaio, o enfraquecimento da ideia de razão que, por um lado, pode ser pensada na crise do fundamento da metafísica cristã (por exemplo, as provas da existência de Deus, a própria noção de verdade com lastro em uma grande narrativa da história da salvação), ou, por outro lado, na crença em uma racionalidade orientada pelo projeto de uma história da emancipação do ser humano (outra grande narrativa, mas agora secularizada e presidida inicialmente pelos filósofos franceses iluministas).

Procuremos entender como a poesia de Daniel Faria solicita uma modalidade de exegese ou, simplesmente, de leitura capaz de articular e tensionar aquilo que é característico da fé cristã e da própria contemporaneidade. Comecemos por interrogar as condições mínimas ou básicas para que o ato de leitura de um poema, como o do poeta português, possa acontecer.

\section{LER O CORPO INTRANSPONÍVEL DO POEMA}

Um bom meio de conhecer a alma é olhar o corpo. Paul Claudel

O que seria do nosso pequeno eu se não conservássemos uma interminável conversa em nosso íntimo? Se o ato de leitura pode ser uma experiência de solidão, como geralmente costuma ser, ou de um robusto exercício espiritual, como promete a civilização da escritura a qual pertencemos, é porque, primeiramente, seu aprendizado solicitou algum tipo de "comunhão" entre a voz que ensina e o ouvido e os olhos que acolhem tal aprendizado. De resto, a aquisição da nossa linguagem depende, em que pesem diversos fatores fisiológicos e neurológicos, de que um outro ser humano nos dirija primeiro a palavra.

Ler é um exercício que pressupõe uma comunidade de leitores. Também é uma possibilidade da criação artística entendida como transfiguração da linguagem, encarnação do verbo na textura de uma sintaxe, de um ritmo e de uma proposta de sentido. De fato, quando lemos, cultivamos a promessa de uma hermenêutica do poema, por exemplo, como compreensão de si por meio de um outro (RICOEUR, 1990, p. 57). Contudo, a leitura solicita uma relação afetiva e uma abordagem descritiva por parte de quem se propõe estudar uma obra, para penetrá-la em seus meandros e abrir com isso horizontes insuspeitados à compreensão da condição humana. E essa condição, a depender do tempo e da expe- 
riência cultural, traz Deus como questão, como ocorre na poesia de Daniel Faria. De todas as possibilidades da leitura, se nossas preferências caírem sobre a poesia, por exemplo, devemos nos preparar para algo fundamental nessa experiência: a poesia é um ato irredutivel a conhecimento (PÉCORA, 2004, p. 308). O que isso quer dizer? Que há uma singularidade expressiva no ato de produção poética que se furta às malhas do conceito e da categorização das ciências ${ }^{1}$.

A ideia de que uma metáfora ou uma imagem poética é intraduzivel na linguagem conceitual pode espantar quem, por dever de oficio, necessita ensinar a literatura. De que maneira um professor do nivel fundamental ao superior ou um crítico poderia justificar a sua profissão, se há sempre um déficit cognitivo e expressivo entre a tradução de uma linguagem para outra e seu eventual ensino? Isso nos levaria à incômoda pergunta: é possivel ensinar e dissertar sobre o poema ou qualquer obra literária?

Transformar uma engenhosa metáfora sobre o amor em uma lição moral ou pedagógica para nosso consumo pessoal ou coletivo pode se revelar uma experiência frustrante, pois, afinal, não existiriam outros insumos a nossa disposição, mais eficientes, mais práticos e convincentes? Então, se não há sabedoria e tampouco pílulas filosóficas nas figuras da linguagem poética, o que seria possivel encontrar em versos como os que transcrevemos a seguir?

\section{EXPLICAÇÃO DA DÚVIDA}

Do seu próprio corpo se alimenta

E a sua obesidade é a aflição

(FARIA, 2009, p. 113).

Que dúvida é essa que não produz ou não contém na sua gênese a própria figura da alteridade ou do outro, mas que encerra um solipsismo ou uma comorbidade? Como compreender essa dúvida na qual a obesidade, a autofagia e a aflição descrevem aquilo que é a atividade mais cara ao pensamento: a pergunta?

A resposta não se dá apenas com a exegese do poema citado, é necessário construir um trânsito entre a sua ocorrência e os tantos poemas que compõem a obra de Daniel Faria. Contudo, a imagem da dúvida, alimentando-se do seu próprio corpo, e o sentimento de aflição, sendo produtor da obesidade, indicam algo tão elementar para a justa compreensão de um corpo. Ele é uma encruzilhada entre pensamento e emoção. Do apego mais disciplinado a uma das expressões do pensamento (a dúvida), nasce a emoção mais indisciplinada que afeta corpo e alma (a aflição).

Ainda que não saibamos propriamente qual é o estatuto dessa dúvida, que expande de tal forma o pensamento em um círculo vicioso, na intranquilidade do espírito ou na obesidade do corpo, é possivel desenhar uma primeira hipótese de trabalho ("o corpo do poema é intransponivel"). Esse corpo é intransponivel no sentido de que por mais que dele extraiamos a fórceps, por cesariana ou em uma espécie de parto natural, o que ele quer significar, ainda assim não conseguimos substituir de forma absoluta a presença imediata do poema pela interpretação dele. Isso não quer dizer que os registros críticos e hermenêuticos sejam desnecessários, eles apenas não são suficientes. As múltiplas leituras de um

1 Para uma discussão sobre o estatuto da arte, não entendida como um tipo de conhecimento, conferir Gilson (2010, p. 85-104). 
poema não provam nada a respeito de um infinito hermenêutico, apenas atestam a sedução pela presença inesgotável da materialidade linguística do texto poético. Não por acaso havia antigamente, nos anos iniciais da formação escolar, a prática de decorar textos poéticos. E não são raros os testemunhos de pessoas que levaram consigo a memória desses textos para o resto de suas vidas. Presença incorruptivel do corpo do poema na memória pessoal. Corpo intransponivel. Corpo místico.

Ao círculo vicioso da dúvida obesa poderíamos contrapor o círculo virtuoso da aposta hermenêutica? As reações experimentadas na leitura do poema, que podem ser espontâneas ou apreendidas em um curto ou longo trajeto de formação, conduzem-nos à hermenêutica do poema, que seria também hermenêutica do leitor, porque haveria no poema as condições de sua interpretação, o que chamariamos também de uma hermenêutica no poema, na medida em que seus marcadores semânticos ou percursos figurativos constituiriam as mediações para o leitor se entender diante do mundo ofertado pela criação artística. Esse círculo virtuoso de interpretação entre leitor e poema é possivel, ao menos na poesia moderna, na medida em que tal programa hermenêutico se encarna na intensa prática metarreflexiva do texto poético, mas não apenas isso, evidentemente. Dito de um modo mais simples e direto, o poema lê o leitor e vice-versa. Ou ainda: o leitor se lê no e pelo poema.

$\mathrm{O}$ fato de que em vários poetas modernos encontram-se tematizados e ordenados os princípios constitutivos da poesia é algo suficientemente explorado pelos críticos ao longo do século XX. Os poemas intitulados "Arte poética" tornaram-se comuns e se constituíram em um dos protocolos de criação e de leitura da obra de um poeta moderno. É como se o poeta pegasse o leitor pela mão e lhe mostrasse qual o caminho mais promissor para entendê-lo. Poemas dessa natureza diriam mais dos procedimentos de base, que permeiam a atividade criadora de um poeta, do que a exaustiva e fastidiosa empresa critica.

Em um poema curto, composto por duas estrofes de dois versos, e marcado por certa concisão linguística, Daniel Faria explica o poeta de dentro do poema com a imagem do homem que ara a terra.

\section{EXPLICAÇÃO DO POETA}

Pousa devagar a enxada sobre o ombro

Já cavou muito silêncio

Como punhal brilha em suas costas

A lâmina contra o cansaço

(FARIA, 2009, p. 101).

Mas o que esse homem cava em terreno impronunciável? Nas palavras precisas do poema, "muito silêncio". Seu instrumento de "escrita" é uma enxada, que, posta sobre seus ombros, brilha "como um punhal". De instrumento de vida (a enxada) àquele de morte (o punhal), da palavra ao silêncio, da dimensão acústica à ótica, o que acompanhamos é um eu lírico que se equilibra entre a labuta extenuante e a celebração vigorosa que é dado contemplar ou simplesmente ver. É a lâmina contra o cansaço. Não seria exagero dizer que o poeta repete no gesto de arar a terra a máxima beneditina: "Orat et labora". Leiamos novamente o poema. 


\section{EXPLICAÇÃO DO POETA}

Pousa devagar a enxada sobre o ombro

Já cavou muito silêncio

Como punhal brilha em suas costas

A lâmina contra o cansaço

(FARIA, 2009, p. 101).

A levar a sério o título do poema, o que tais versos explicam sobre a "essência" do poeta? A primeira coisa, talvez frustrante para quem esperasse uma definição soberba da arte poética, é que o poeta tem um corpo e ele faz uma atividade de natureza prática para sua sobrevivência, se puxarmos todos os fios de Ariadne que conectam e orientam a ancestral tarefa de lavrar e extrair da terra o sustento diário. Porém, um segundo aspecto é que esse fazer demonstra um apreço incisivo pela luz, a despeito de ou contra o cansaço. Lemos o poema e imaginamos um lavrador de costas onde a efigie silenciosa de seu corpo retesa todo o significado do que se pensa sobre a palavra "alma". É um caminhante que recolhe em seu corpo a promessa do corte afiado da lâmina, a ceifar o cansaço resultante da labuta de cavar o silêncio. O poeta não é um agrimensor do silêncio, não geometriza o espaço da lavra, apenas cava para semear ou extrair a matéria do seu oficio. Não sendo o poeta um medidor (um matemático pensador), mas alguém que desfere golpes, que bate com a enxada na matéria bruta silenciosa, é a paixão pelo concreto e pelo sensível que dá compleição ao corpo e à alma. Mais do que pensar o poeta ou o poema, é necessário vê-los e escutá-los naquilo que são e não naquilo que supostamente escondem aos olhos do leitor e que seria o secreto e verdadeiro sentido das coisas e das palavras. Porém, será disso mesmo que esse poema ("A explicação do poeta") e um outro ("Arte poética") querem nos convencer? Vejamos.

\section{UM RITUAL ERÓTICO: A DIALÉTICA DA VESTE E DA NUDEZ}

ARTE POÉTICA

A palavra despe-se

O silêncio despe-se

Nus

Os sexos ardem

Os seios da palavra

Os músculos do silêncio

O silêncio

E a palavra

O poeta

E o poema

(FARIA, 2009, p. 386).

Comecemos a análise desse poema por um truísmo: despir é literalmente tirar as vestes, mas o que resta quando se subtraem as vestes do corpo? Ou na cirúrgica formulação de G. Agamben (2010, p. 95), "Que se conhece quando se conhece uma nudez?”, questão que também poderia ser apresentada da seguinte 
maneira: qual o significado da corporeidade nua? Antes de passar daquele truísmo a essa questão de ordem especulativa e com laivos metafísicos, façamos perguntas ainda mais pedestres.

Por exemplo, deve ter ocorrido de imediato ao leitor a presente indagação: em quais circunstâncias concretas se pratica o ato de despir? Descrevê-las, ainda que sucintamente, torna-nos aptos a dar mais um passo e perguntar: tais ocasiões, que favorecem o ato de despir, oferecem quais sentidos ou prometem quais configurações simbólicas?

Desnudamo-nos como parte de um hábito de higiene (por exemplo, quando tomamos um banho); como a manifestação mais efusiva do lúdico (para brincar no mar, nos lagos, na piscina, embora isso seja mais comumente aceito no período da infância); como parte de um ritual erótico (o jogo travado de regras no qual a dialética do ocultar e do revelar dão o ritmo para os corpos). Despimo-nos para que possamos ser examinados pelos médicos (a semiologia das doenças); como expressão de um ritual religioso, quando na antiga tradição cristã, despiam-se os catecúmenos antes de submergi-los nas águas batismais (a transformação ontológica da natureza humana).

Dessa descrição dos lugares-comuns do ato de se despir, fica evidente que a veste (a roupa) é norma social com forte acento prático e simbólico em certas comunidades, espécie de dobradiça entre o mundo da natureza e da cultura. Se como norma faz aparecer um princípio de racionalidade em nossa relação e diferenciação com o mundo ou com os outros, em contrapartida, da perspectiva de um olhar mais comezinho, a veste tem a função de nos proteger das intempéries da natureza, uma vez que, diferentemente dos animais, não possuímos pelos ou penas.

Nossa epiderme, exposta ao inclemente sol ou excessivo frio, padece mais fortemente do que a pele de outros animais. Assim, seguindo a linha desse raciocínio, a nudez recobre tanto o campo moral quanto o campo das necessidades fisiológicas e naturais. A nudez evoca a fragilidade da nossa epiderme, mas também as sensações táteis e visuais desfrutáveis com a contemplação do olho ou a carícia das mãos. Mas, se na nudez o que está em jogo é algo que se expõe ao olhar e de uma perspectiva cristã, algo que pode ser motivo de vergonha (pensemos na cena de Adão e Eva tomando consciência de que estão nus), que importância teria para o poema "Arte poética", de Daniel Faria, o fato de palavra e silêncio se despirem?

Não sabemos quais são as vestes que ambos retiram, tampouco qual seria a relação entre esse ato de despir e o ato da criação poética. Não sabemos, por exemplo, se desnudar (mostrar, revelar, tomar consciência) se alinha ou se contrapõe ao ato de metaforizar. Se à metáfora compete amplificar o campo semântico dos construtos linguísticos, à cena de desnudamento caberia uma redução ou ampliação do corpo "poético"?

Para dar sequência à interpretação desse poema de Daniel Faria, levemos no percurso argumentativo esta dúvida: a metáfora desnuda ou oculta? Ou, ainda, a metáfora mantém em estado de emergência a tensão entre mostrar e esconder? Se, na metáfora ou no corpo do poema, a tensão não se resolve na extração de um conceito ou de um conhecimento ensinável ao leitor, qual a necessidade ou a compulsão que sentimos pela leitura de obras poéticas?

Uma segunda hipótese de trabalho, muito modesta, poderia aqui ser formulada: o silêncio se despir significaria "falar"; a palavra se despir significaria "calar". 
Então, o silêncio falaria e a palavra calaria. Ambos se metamorfoseariam, passariam por uma mudança ontológica, deixariam de não ser para ser algo diferente, como em uma espécie de fusão amorosa em que as subjetividades são feridas ou esvaziadas. Desse esvaziamento, e para que o real intercâmbio ou a interface verdadeira aconteça, emergem uma política e uma ética da imaginação: o sensivel não é transcendido, como em uma ascese racional, mas encarna uma encruzilhada, para ficarmos com a percuciente imagem de Jacques Maritain, qual seja, "a poesia é a encruzilhada do singular" singularidade mais expressiva. Porém, como disse, essa é uma hipótese muito modesta ou uma tentativa brutal de sintese.

A metáfora da encruzilhada encontra-se presente em um poema sem título do livro Dos liquidos, de Daniel Faria (2009, p. 268):

Voz pisada como o vinho

De onde bebo

A perda dos sentidos

Silêncio tão pisado que não verte

O verbo

Silêncio encruzilhado

Na voz do homem calado no caminho.

De um "silêncio encruzilhado", pode-se afirmar que é um silêncio crucificado, caso se queira evocar o aspecto religioso latente no primeiro adjetivo. Estar em uma encruzilhada é reconhecer que a decisão a ser tomada, por implicar algumas possibilidades, significa liberdade, mas também a capacidade de se sacrificar ou de assumir o risco de uma transformação, afinal, escolher uma possibilidade significa abandonar as demais. Contudo, a encruzilhada é o espaço onde realidades distintas ou sentidos diferentes se manifestam. E se escutarmos ainda mais as ressonâncias da imagem, perceberemos que a encruzilhada é um local sagrado.

Como local onde o sagrado se manifesta e dele se faz algum tipo de experiência, a imagem da encruzilhada com seu potencial de escolha pode paralisar o caminhante. Primeiro, metonimicamente, na voz que se cala; depois, na totalidade do corpo que hesita entre recuar, prosseguir em frente, à esquerda ou à direita: coordenadas espaciais que figuram a imagem da cruz e de um pathos (uma paixão) que aguça a experiência do sagrado e da busca espiritual por meio dos simbolos.

Da expressão "encruzilhada do singular e do contingente", presente em Jacques Maritain, à imagem do "encruzilhado silêncio", de Daniel Faria, o que há de comum é a recorrência do sintagma, mas a diferença é que, em Maritain, ele é um construto argumentativo que aspira à ordem conceitual para se apreender o que seria o específico do fenômeno poético, ao passo que a imagem de Daniel Faria é nó indissolúvel entre o fenômeno e o discurso a respeito dele. Se o filósofo explica o fenômeno recorrendo à imagem da encruzilhada, o poeta

2 A esse propósito, valeria a pena citar este excerto de Maritain, em que se procura distinguir a metafísica da poesia: “A metafísica anda à cata de essências e definições, a poesia se contenta com qualquer forma que brilhe, de passagem, com o menor reflexo de uma ordem invisível. Uma isola o mistério para conhecê-lo; a outra, graças aos equilíbrios que constrói, o maneja e utiliza como uma força desconhecida... Poesia, neste sentido, não é evidentemente, privilégio de poetas. Força todas fechaduras, espera-vos onde menos a imagináveis encontrar" (MARITAIN, 1947, p. 9-10). 
apresenta a imagem como explicação e realização do fenômeno poético. Em ambos os casos, a imagem está presente. Contudo, no filósofo, ela prepara o degrau na escada do conceito; no poeta, a imagem é degrau (parte) e a escada (todo) é meio e fim, por paradoxal que isso possa parecer. E mais: não atuaria a imagem poética na condição de revelar e ocultar ao mesmo tempo? É o que discutiremos na questão do tema da nudez, fazendo um desvio pelas reflexões de Agamben (2010).

\section{O DISPOSITIVo TEOLÓGICO: VESTE (GRAÇA) E NUDEZ (NATUREZA)}

Figura 1 - Vanessa Beecroft, Berlim, 2005

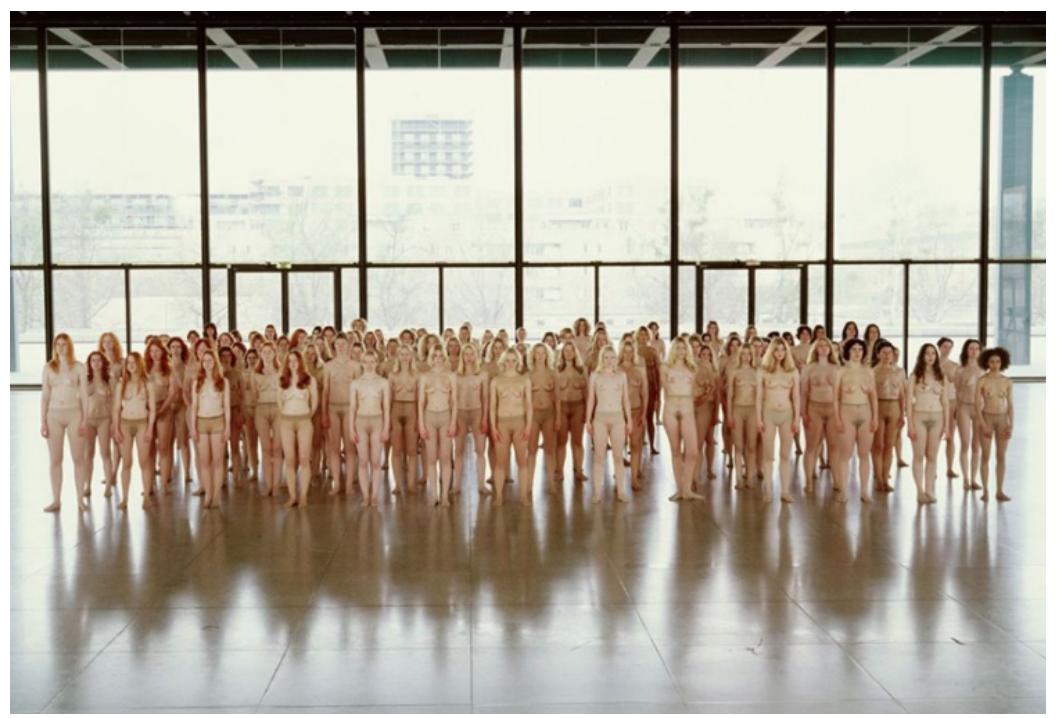

Giorgio Agamben (2010, p. 71-105), em seu ensaio Nudez, evoca uma cena, uma exposição artística de Vanessa Beecroft, conforme imagem acima, ocorrida em Berlim no ano de 2005, em que um grupo de mulheres estão nuas (na verdade, elas trajam collants transparentes que simulam nudez) enquanto um outro grupo de visitantes adentra o recinto da exposição para flagrá-las em sua suposta nudez. O filósofo italiano afirma que um processo curioso e uma reversão da cena ocorrem nessa exposição performática, pois a posição das mulheres (o gestual e seus olhares inquisitivos), que, como dizíamos, não estão nuas, faz falhar aquilo que supostamente seria o cerne da performance: desnudarem-se diante do grupo de visitantes. De fato, se levarmos às últimas consequências o raciocinio de Agamben, quem são desnudados pelo simulacro de nudez dos corpos femininos são justamente os visitantes, curiosos e ávidos pelo que se promete acontecer na cena artística.

Portanto, os desejos e as intenções dos visitantes é que são despidos no acontecimento artístico. Esse jogo artístico entre o olhar expectante do visitante e a performance elaborada pela artista é, segundo Agamben, atravessado por um dispositivo teológico da nudez, que a sua análise fará questão de descrever e desativar ao final de seu ensaio. Aliás, para Agamben, a nudez é constituída de uma marca teológica, posta de modo paradigmático na cena da expulsão do paraíso 
(Gênesis 3). A primeira consequência depois que o casal primevo prova do fruto da árvore do conhecimento do bem e do mal é que ele toma consciência de que está nu.

Figura 2 - A expulsão do paraíso, de Albrecht Dürer (1471-1528)

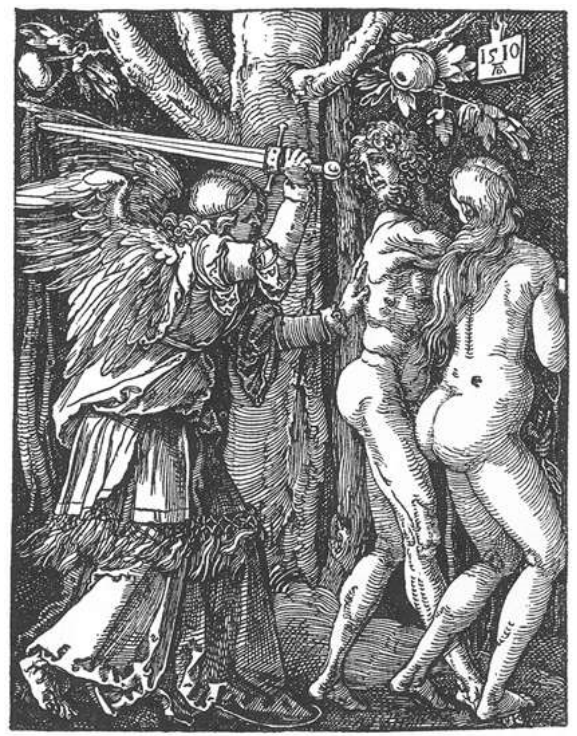

O capítulo 3 do livro do Gênesis contém, em que pesem as infinitas possibilidades de leituras hermenêuticas sobre o seu sentido, o núcleo duro das noções de nudez, justiça e pena: querubins expulsam o casal primevo pelo desrespeito à ordem divina e, ato contínuo, guardam a entrada do paraíso com espadas flamejantes para que Adão e Eva não retornem a ele.

Da cena brevemente relatada, conclui-se que não há lei sem demonstração de força. Separação e privação são decorrências lógicas dessa força da lei divina; também são categorias do âmbito do sagrado e operam simbolicamente para a divisão entre tempo e eternidade. Nenhuma pena é infinita, se a perspectivamos do ângulo da história da salvação: todo corpo é mortal e sujeito à temporalidade. É claro que a essa punição terrena, a que é submetido o casal primevo, pode se transformar em danação eterna, cuja imagem mais veemente é a do inferno, apesar de a "realidade teológica" dessa categoria ser passivel de discussão ao longo da tradição judaico-cristã.

Na gravura de Albrecht Dürer (1471-1528), pintor renascentista, a nudez do casal, com nádegas expostas e a face crispada de Adão, contrasta brutalmente com as vestimentas angelicais e a espada empunhada do querubim. A justiça divina nunca está despida e requer gestos ostensivos e dramáticos para convencer e educar. Quem deve ser despido e desnudado é o réu. Faz parte da liturgia do poder opor a nudez do infrator à vestimenta do garante da ordem. Espada, vestimenta e gestos incisivos investem de autoridade o guardião da ordem. Contrastando com as vestes do querubim, aparece a corporeidade nua que é a ausência da graça. É esse jogo entre a veste divina (sinônima de graça) e a nudez 
da culpa e do corpo (expressão da natureza) que organiza a liturgia da lei, seduz os destinatários da mensagem religiosa porque atualiza a cena primitiva da expulsão e, por fim, constitui o que Agamben chama de dispositivo teológico.

Pode-se perguntar se a crítica literária que praticamos não procede ao modo do querubim de Albrecht Dürer, que, solenemente vestido e com gesto ostensivo, faz aflorar nossa indignação e obsessão diante da nudez e presença dos corpos. Em vez de um querubim empunhando sua espada, teríamos leitores vestidos com suas tralhas teóricas ou seu equipamento conceitual a nos advertir que a visibilidade dos significantes e da letra do poema é aparência superficial de algo mais profundo, mais significativo.

Todavia, o que tudo isso tem a ver com o poema de Daniel Faria, intitulado "Arte poética"? Que analogia haveria entre a cena performática, evocada por Agamben, em que os visitantes são despidos dos seus desejos e intenções, a gravura do pintor Dürer, na qual o casal primevo tem expostas as partes pudendas de seu corpo, e o poema "Arte poética", de Daniel Faria, que ritualiza de um modo minimalista o desnudamento de duas realidades essenciais ao poema: o silêncio e a palavra?

Semelhantes aos ávidos frequentadores de performances artísticas, mencionados por Agamben em seu ensaio, também nossos desejos são despidos e revelados no ato de leitura de um poema, enquanto esse último, que evoca em seu núcleo semântico o tema da nudez, permanece vestido com a graça da metáfora (no sentido teológico e estético). O desnudamento completo do poema, no ato da leitura, caso isso fosse possivel, significaria reduzi-lo à condição de objeto inerte à disposição do olhar concupiscente. Significaria o poema não na condição de um corpo, dotado de "vontade própria", mas na qualidade de carne trêmula e de letra morta. Esse desnudamento completo seria não apenas uma espécie de infração moral, mas uma mudança metafisica ou ontológica no próprio ser do poema. Seria a negação de que o poema é criação, ou seja, é ao mesmo tempo o fruto proibido (o conhecimento), o casal primevo (os leitores), a serpente irônica e o criador (a potência e ato expressivo da linguagem).

Dessacralizado e ofertado na sua pura visibilidade, o poema seria somente um símile do fruto proibido da árvore do conhecimento do bem e do mal: ao comê-lo, ao devorá-lo com nossos olhos, esses se abririam a ponto de nos reconhecermos como pequenos deuses. Contudo, a polissemia da palavra poética não resguardaria a linguagem da mecânica luciferina ou ofidica da inveja ("Sereis como Deuses", diz a Serpente)? A polissemia evitaria que a explicação fosse cabal e desnudasse completamente o corpo do poema. Mas, se ela for capaz de realizar isso, estaria preservado o caráter sagrado da criação poética? Talvez, a crer que a criação poética é criação verdadeira, isto é, faz aparecer algo que antes não existia.

Lendo o ensaio de Agamben a partir dessa analogia entre dispositivo teológico da nudez e gesto crítico, é como se com esse último repetíssemos "a falha" ontológica dos nossos pais ancestrais ou reiterássemos consciente ou inconscientemente o binômio veste (graça) e nudez (natureza). É “como se” esse dispositivo trouxesse a paixão, o ciúme, a inveja e a curiosidade congênitas da natureza humana. É por isso que Agamben argumenta em seu ensaio que é preciso desarmar esse dispositivo teológico, resquício da metafísica da Presença, que promete haver, por trás de um sentido manifesto ou da presença singular, um outro latente e mais decisivo. 
Porém, pensando com e contra Agamben, seria de se supor se o poema de Daniel Faria não contrariaria a estratégia crítica do filósofo, ao pretender desarmar tal dispositivo. E mais: lendo os poemas de Daniel Faria, nós nos perguntaríamos se é possível uma leitura não teológica do poema, na medida em que a transcendência ou a suposição de que ela exista é o que nos faz apostar no "sentido do sentido", para usar uma expressão que se encontra na base da leitura crítica de George Steiner, antipoda das propostas antiteológicas de Agamben. Refiro-me ao livro Presenças reais (STEINER, 1993), para quem Deus não é um fóssil na linguagem, mas Presença real e viva. Sem considerar essa Presença real, como compreenderíamos os seguintes versos de Daniel Faria?

Quero a fome de calar-me. O silêncio. Único

Recado que repito para que não me esqueça. Pedra

Que trago para sentar-me no banquete.

A única glória do mundo - ouvir-te. Ver

Guando plantas a vinha, como abres

A fonte, o curso caudaloso

Da vergôntea - a sombra com que jorras do rochedo

Quero o jorro da escrita verdadeira, a dolorosa

Chaga do pastor

Gue abriu o redil no próprio corpo e sai

Ao encontro da ovelha separada. Cerco

Os sentidos que dispersam o rebanho. Estendo as direções, estudo-lhes

A flor - várias árvores cortadas

Continuam a altear os pássaros. Os caminhos

Seguem a linha do canivete nos troncos

As mãos acima da cabeça adornam

As águas nocturnas - pequenos

Nenúfares celestes. As estrelas como as pinhas fechadas

Caem - quero fechar-me e cair. O silêncio

Alveolar expira - e eu

Estendo-as sobre a mesa da aliança

(FARIA, 2009, p. 279).

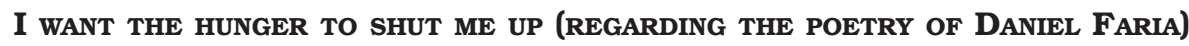

Abstract: This essay discusses Daniel Faria's poetics and his insertion into a spiritual and biblical tradition. The thematic core of the analysis, formed by the binomials "silence and word" and "dress and nudity", is accompanied by the formulation of two working hypotheses: the first states that the poem is an insurmountable body, as the expressive singularity of the artistic language does not translate itself completely into the conceptual field of a scientific discipline; the second hypothesis proposes that this irreducibility of the poem to a conceptual field is due to the statute of metaphor (the polysemy of meaning).

Keywords: Daniel Faria. Nudity. Grace. Literature and Bible. Metaphor. 


\section{REFERÊNCIAS}

AGAMBEN, G. Nudez. Tradução Miguel Serras Pereira. Lisboa: Relógio D’Água, 2010.

ALVES, I. A poesia de Daniel Faria: a claridade da morte. Via Atlântica, n. 11, p. 103-115, 2007.

BENTO, S. A regra de São Bento: latim-português. Tradução João Evangelista Enout. 4. ed. Rio de Janeiro: Lumen Christi, 2017.

FARIA, D. Poesia. Vila Nova de Famalicão: Quasi, 2009.

GARCIA, M. Daniel Faria, vinte anos após a sua morte. Ponto SJ - Portal dos Jesuitas em Portugal, 8 jul. 2019. Disponivel em: https://pontosj.pt/especial/ daniel-faria-vinte-anos-depois-da-sua-morte/. Acesso em: 3 dez. 2019.

GILSON, É. Introdução às artes do belo: o que é filosofar sobre a arte? Tradução Érico Nogueira. São Paulo: É Realizações, 2010.

MARITAIN, J. Arte e poesia. Tradução Edgar de Godói da Mata-Machado. Rio de Janeiro: Agir, 1947.

PÉCORA, A. Literatura como ato irredutivel a conhecimento. Remate de Males, v. 34, n. 2, p. 307-312, 2004.

PESSOA, F. Mário de Sá-Carneiro (1890-1916). In: PESSOA, F. Obra em prosa. 11. ed. Rio de Janeiro: Editora Nova Aguilar, 2005. p. 455-456.

RICOEUR, P. Interpretação e ideologias. Tradução Hilton Japiassu. 4. ed. Rio de Janeiro: Francisco Alves, 1990.

STEINER, G. Presenças reais. Tradução Miguel Serras Pereira. Lisboa: Editorial Presença, 1993. 